\title{
Evaluating changes in the Bank of Spain's interest rate target: an alternative approach using marked point processes*
}

Juan J. Dolado and Ramón María-Dolores

Department of Economics Universidad Carlos III de Madrid, c/Madrid 126, 28903 Getafe (Madrid), Spain; e-mail to: dolado@eco.uc3m.es

Universidad de Murcia; e-mail to: ramonmar@um.es

\section{Introduction}

As in many other countries, the econometric analysis of the determinants of the monetary-policy stance of the central bank in Spain has been mainly centered around the estimation of dynamic linear-regression models in the spirit of the so-called 'Taylor rules' (see, e.g., Gali, 1999, and María-Dolores 2001). As is well known, those rules characterise appropriately the optimal policy-reaction function of a central bank in terms of the adjustment of a short-term interest rate under its control (see Clarida et al., 1999). According to the mainstream work in this line of research, adjustments in the interest-rate target are typically related to inflation and output gaps in a closed-economy framework and, besides those variables, to exchange-rate and foreign interestrate terms when considering open economies (see, e.g., Taylor, 1993 Svensson, 1997, and Clarida et al., 1998).

However, such an approach turns out to be too restrictive when trying to analyse some distinctive features that characterise the intervention of any central bank. First, the interest rate under control is changed irregularly, as often as once a week or as seldom as once a term. And secondly, it is adjusted in discrete increments, typically of 25 basis points, rather than in a continuous fashion. In line with these two characteristic features, our goal is precisely to

${ }^{*}$ We are grateful to A. Alba, C. Alonso-Borrego, M. Arellano, R. Carrasco, J.I.Garcia-Pérez, A. Gorostiaga, R. Mora, D. Veredas, an editor, two anonymous referees, and seminar participants usual disclaimer applies. 
investigate, in the context of Spanish monetary policy, which are the main determinants of both the arrival times of interest-rate adjustments and their magnitude, conditionally on the decision to intervene. The analysis of both issues seems to be very relevant in learning how monetary policy is being conducted by central banks in the recent past. In this sense, it can provide interesting complementary evidence to that drawn from the "Taylorides apprach. When analysing those two features, however, one should take into account that the infrequent and discrete nature of the interest-rate adjustments renders the standard time-series techniques inappropriate since they are devised to model continuous data arriving at fixed intervals of time. Therefore, statistical techniques able to deal with data arriving at imegula intervals are needed. For this reason, we turn to an alternative econg methodology based on the theory of the so-called marked point processes (see Engle and Russell 1997, 1998). In so-called marked point processes (see Engle and Russell, 1997, 1998). In the statistics literature, a marked point process is defined as a sequence of orderly times where a number of events occur at each point in time and has associated to it an information process at each event time. Hence, they are very well suited to analyse data which arrive at irregular intervals and that change in discrete increments, turns out to be the case of the interest-rate adjustments implemented by central banks.

Accordingly, the proposed methodology provides a useful econometric tool to address a number of interesting questions which cannot be tackled with the standard 'Taylor-rules' approach. Those questions range from What determines the arrival times and the size of interest rate changes? to Is an intervention more likely to occur when there has not been one for a long time? More precisely, our approach is based upon the bim model to determin the prob model to determine the probability of an intervention by the Bank of Spain a each point in time (the so-called events or points) and an ordered probit mode to determine the size of the interventions, conditionally on having decided to intervene (the so-called marks). Estimates obtained from both separate and joint estimation procedures of the parameters underlying both probabilities will be presented to assess how robust are our findings to the choice of estimation method.

To our knowledge, there are a number of empirical studies in the literature which use variants of this econometric technique to deal with somewhat similar issues to the ones considered in this paper. For example, Eichengreen et al. (1985) analyse the behaviour of the Bank of England under the interwar gold standard using an ordered probit to model the inder policy. In particular, they are interested in testing whether the monetary authority raised interest rates when there was a decline in foreign reserves while, by contrast, refrained from adjusting them when foreign reserves increased. Davutyan and Parke (1995) carry out an extension of the previous study to a sample period running from 1890 to 1908 . More recently, for purposes close to ours, Jordá (1997), Fischer and Zurlinden (1998) and Hamilton and Jordá (2000) have used a variant of this approach, i.e. the socalled Autoregressive Conditional Duration (ACD) model proposed by Engle and Russell $(1997,1998)$ and Engle (2000). Among those three papers, the first and the third ones above consider a generalized class of Autoregressive Conditional Hazard (ACH) models to analyse the evolution of the Federal Funds Rate Target in the U.S. This class of models includes as a special case a discrete-time version of the ACD framework which turns out to be a convenient model to forecast not only whether a change in the Fed Funds Target will take place at a given moment of time but also the magnitude and the direction of the change. The second paper, in turn, studies the behaviour of the exchange-rate interventions by three central banks (the Bundesbank, the Federal Reserve and the Swiss National Bank), albeit restricting the analysis only to the case of events, with the question in mind of finding whether there is evidence in favour of a 'self-exciting' behaviour in the duration procss of interventions, namely, if the time interval between interventions tends to be clustered, demonstrating a high degree of persistence in time.

Our paper contributes to the previous literature in at least two main respects. First, from an econometric viewpoint, it looks at the issue of the possible failure of weak exogeneity which arises when events and marks are separately estimated, as it is often the case in practice. Engle and Russell (1998) have argued that, when that assumption fails, separate estimation of the (1998) have a in the consistent, estimates. Thus, it seems relevant to gauge how important this lack of efficiency might be in our case. We do so by comparing the estimates obtained from the separate estimation of a probit model (for events) and an ordered probit model (for marks) with those obtained from maximising an approximation of their joint likelihood provided by a sequential probit model. Secondly, from an economic viewpoint, we investigate the issue of the possible existence of asymmetries in the way the Bank of Spain adjusted the
interest-rate target in response to changes in the determinants of its policyreaction function. This is a hypothesis of growing interest in both the empirical and the theoretical literature about the way central banks conduct monetary policy nowadays (see Ravn and Sola, 1996, and Dolado and MaríaDolores, 2001a). Specifically, in the context of the derivation of optimal monetary-policy rules (see Svensson, 1997), either the existence of a nonlinearities in the Phillips curve or the presence of asymmetric preferences
on inflation or output in the loss function of the central bank could lead to a different response by the monetary authority when facing deviations of different sign or magnitude in inflation or output gaps (see Schaling, 1999, 
and Dolado et al., 2001b). The intuition for this asymmetric behaviour is simple. For instance, if we assume that there is downward nominal-wage rigidity in the economy, then the Phillips curve turns out to be convex in the inflation-output gap space. Hence, in order to maintain price stability, central bank would tend to raise interest rates by a larer amount why, the output gap is positive than it would tend to cut the interest negative Likewise, if the cental bank were to assign a larger weight in function to downward central bank were to assign a larger weight in its loss function to downward deviations in output from its normal level than to upward deviations, monetary-policy stance will be chosen so as to make the probability of erring on the side of tightness smaller than the probability of erring on the side of ease, implying larger interest-rate cuts in dowabily of interest-rate increases in upturns.

Proceeding in that way, we obtain several interesting results concerning the conduct of monetary policy in Spain over the period 1984-1998 when the Bank of Spain was using a short-term interest rate as its policy instrument. First, we find that the timing of interventions responds systematically to both a number of time-varying covariates included in the information set of the central bank and to the durtion since the last interestrate adjustment In particular inflation changes and the tim the last adjustment turn out to be the two strongest determinants of the arrival time of interest rate changes. As regards the existence of asymmetric effects, we find that the Bank of Spain had a propensity to intervene more frequently when: (i) inflation was increasing than when it was decreasing, (ii) the $\mathrm{Pta} / \mathrm{DM}$ exchange rate was depreciating than when it was appreciating, and (iii) when the economy was undergoing a recession th when there was in an expansion. Finally, evidence is also found in favour the so-called 'duration effect, implying that the longer the so-called 'duration effect', implying that the longer the period elapsed since the last intervention was, the larger the next interest rate change tended to be. At this stage, let us conclude by pointing out a particularly useful application of the methodology proposed here which is left for future research. It could be applied to provide comparative evidence, acros te EMU Member States, on whether there have been significant chases the way monetary policy was being conducted by she waring national central banks during the second half of the $1990 \mathrm{~s}$, in the run-up to EMU, relative to the way it has been conducted by the ECB after 1999, when monetary policy control was handed to Frankfurt.

The rest of the paper is organised as follows. Section II offers a brief explanation of the empirical methodology which is used throughout the paper and discusses in some detail the statistical framework underlying the estimation of the stochastic processes for events and marks. Section III analyses the arrival times of the interest-rate changes implemented by the Bank of Spain through a probit model, and tests for the possibility of asymetric behaviour. Section IV, in turn, analyses the determinants of the size of interest-rate adjustments, conditionally on the decision to intervene, by means of an ordered probit model. Section $\mathrm{V}$ tries to ascertain, by means of a sequential probit model, how robust are the results obtained in Sections III and IV when compared to those obtained from a joint estimation procedure. Finally, Section VI draws some conclusions.

\section{Econometric Issues}

To measure the stance of monetary policy in Spain we use changes in the marginal interest rate of intervention of the Bank of Spain in the daily interbank-reserves market from 1984 to 1998. The choice of this sample period is dictated for the following reasons. First, there is ample evidence stating that the Bank of Spain only started to have an autonomous control over monetary policy since 1984 , in contrast with the more accommodating stance it had before (see Escrivá and Santos, 1991, and Ayuso and Escrivá, 1996). Second, having Spain joined EMU, the basic control of monetary policy was handed to the ECB after 1999. The interest-rate targets series is taken to be the marginal short-term interest rate of auctions 'Préstamos de Regulación Monetaria' series from January 1984 to May 1990 and the interest rate of 'Certificados de Depósito del Banco de España' (CEBES) series, from May 1990 to December 1998. ${ }^{1}$ Both interest rates represent the marginal target rates at which the Bank of Spain matched the demand and supply for required and excess reserves by the financial system in the daily interbank market and have been taken to be relevant indicators of monetary-policy stance in Spain during the chosen sample period.

As discussed earlier, the evolution of the interest rate target can be characterised by the following two key features: (i) changes are spaced irregularly in time, and (ii) they take place in discrete increments. In the statistical literature, a stochastic process with such characteristics that has associated an information process at each event in time is known as a marked point process. The main goal of this section is to describe such processes in some detail. We proceed in two stages. At the first stage, we consider how to model the arrival times of interventions (events) while, at the second stage, we model the size and sign of the changes in the interest rate (marks), conditionally on the decision to intervene.

A preliminary issue in the analysis, however, is to define how the timing of decisions evolves. In this respect, it is assumed that, at the beginning of each period, the central bank chooses a target for the interest rate, conditionally on 
the information available up to that point, which is subsequently revised to accommodate the arrival of new information on the evolution on the economy. Under this scheme, given that the majority of macroeconomic data available to the monetary authority when taking interest-rate decisions have monthly frequency, we will consider a month to be the relevant unit of time Accordingly, in the sequel, changes in the monetary-policy instrument will be aggregated to that fixed interval of time.

To begin with, it is convenient to describe the statistical process which governs the decision of the Bank of Spain to alter or leave unchanged the interest-rate target, given the information set available at each moment in time. Drawing upon Jordá (1997), we interpret the data as follows. Let $X_{t}$ be a binary random variable, that is assumed to take a value of zero if not $X_{t}$ be a the interest rate takes place during month $t\left(X_{t}=0\right)$, and to be equal to one if a change occurs $\left(X_{t}-1\right)$. Let $Y_{t}$ in turn be the change in month $t$ given that $X_{t}=1$. Finally, con the of predetermined, given that $X_{t}=1$. Finally, consider $B_{t-1}$ to be a $k x l$ vector of predetermined variables known at the decision time (typically including changes in output growth, changes in inflation, deviations of a money growth rate from a target rate, changes in relevant exchange rates, etc.). In this way, the joint density of $X_{t}$ and $Y_{t}$ conditional on information up. In this way, given by:

$$
X_{t}, Y_{t} / Z_{t-1} \sim f\left(X_{t}, Y_{t} / X_{t-1}, Y_{t-1}, B_{t-1}, \theta\right),
$$

which, without loss of generality, can be rewritten as the following product of marginal and conditional densities:

$$
\mathrm{f}\left(\mathrm{X}_{\mathrm{t}}, \mathrm{Y}_{\mathrm{t}} / \mathrm{X}_{\mathrm{t}-1}, \mathrm{Y}_{\mathrm{t}-1}, \mathrm{~B}_{\mathrm{t}-1}, \theta\right)=\mathrm{f}_{\mathrm{l}}\left(\mathrm{X}_{\mathrm{t}} / \mathrm{X}_{\mathrm{t}-1}, \mathrm{Y}_{\mathrm{t}-1}, \mathrm{~B}_{\mathrm{t}-1}, \theta_{1}\right) *
$$

That is, the joint density of marks and events is equal to the marginal density of the events (timing of interest-rate changes), $\mathrm{f}_{1}$, times the conditional density of the marks (size of changes in interest rates) given the current event, $\mathrm{f}_{2}$, all conditional on past information. Under weak exogeneity in marks, namely, when $\theta_{1}$ and $\theta_{2}$ are variation-free parameters, then the Maximum-Likelihood estimator(MLE) of $\theta_{1}$ will be simply obtained from maximizing the marginal $\log$-likelihood corresponding to $f_{1}$. Likewise, the MLE of $\theta_{2}$ will be obtaine from maximizing the conditional likelihood of $f_{2}$

Nevertheless, the possibility that the weak exogeneity property may not hold must be entailed. In this case, as Engle and Russell (1999) have arg not consistent but inefficient estimates of the parameters determining $f_{1}$ and $f_{2}$ will be obtained when each likelihood is maximised separately. For $f_{1} a_{2} f_{2}$ will will be the case when the vector of parameters $\theta_{2}$ is estimated directly from the coniontional density, $f_{2}$, neglecting possible inter-dependences with the vector of parameters $\theta_{1}$ associated with the marginal density, $f_{1}$. However, it seems likely that such a loss of efficiency may tend to decrease as the sample size increases.

Testing for weak exogeneity of $\mathrm{X}$ for $\theta_{2}$ in this econometric specification presents some serious complications relative to the standard testing approaches derived in a dynamic linear-regression framework (see Hendry et al., 1983). This is so since, for example, the use of a logit specification for both densities prevents the implementation of an exogeneity test $a$ l $l a$ Hausman (1978), since logistic sums are not logistic. For this reason, we have chosen a probit specification due to the additive property of normality. Nonetheless, a further problem arises when, as in this paper, the variable that creates the potential endogeneity problem, $X$, is a qualitative binary variable and not a continuous one.

Due to those technical difficulties, we adopt an admittedly ad-hoc informal testing procedure to test for weak exogeneity. First, we estimate separately a probit model for the marginal density of events and an ordered probit model for the conditional density of marks, to be reported in sections III and IV. According to the previous discussion, this first stage will be useful in undertaking a congruent specification search of the relevant variables appearing in each of the two models. However, the estimated coefficients from both models will be consistent but not necessarily efficient if the parameters $\left(\theta_{1}, \theta_{2}\right)$ are not variation free. Next, to check to what extent that is a relevant problem, a sequential probit model will be estimated in section 5 , as a feasible approximation to the joint likelihood of marks and events. In this fashion, proximity of the estimates and their precision obtained under the separate and the joint-estimation procedures will be interpreted as confirmation that the weak exogeneity property holds. By contrast, strong differences between both sets of estimates will signify rejection.

\section{Analysis of events: The arrival times of interest-rate changes}

This section explains how to model the marginal density, $f_{l}$. Its goal is to model how the arrival times of the changes in the interest rate are determined. In doing so, our aim is to address the following questions: (i) What is the probability that the Bank of Spain will change the interest rate during the next month?; (ii) Is there persistence in these interventions?; and (iii) What

macroeconomic variables affect the timing of changes in the interest rate

To tackle those issues we use a probit model where it is assumed that interest-rate changes take place at time $1, \ldots, \mathrm{t}-1, \mathrm{t}, \mathrm{t}+1, \ldots \mathrm{T}$, where $t$ refers to a particular month and $T_{t}$ denotes the number of days elapsed from the last change. Since the variable $X_{t}$ is a binary variable (equal to unity if the 
interest rate is changed in month $t$ and equal to zero otherwise), a probit model is a natural choice to analyse the determinants of the probability of intervention. For this purpose, we assume that this probability depends on a moving average of durations since previous interventions, and on an additional set of predetermined covariates included in the information set of the central bank. For notational convenience, we consider $T_{t}$ and $T_{t-1}$, i.e. the duration since the last and the penultimate change ${ }^{2}$, separately from the other set of variables in the information set, $\mathrm{B}_{\mathrm{t}-1}$. Thus, the model can be written as:

$$
\mathrm{p}\left(\mathrm{X}_{\mathrm{t}}=1 / \mathrm{B}_{\mathrm{t}-1}, \mathrm{~T}_{\mathrm{t}}, \mathrm{T}_{\mathrm{t}-1}\right)=\mathrm{F}\left(\delta^{\prime} \mathrm{H}_{\mathrm{t}}\right)=\Phi\left(\delta^{\prime} \mathrm{H}_{\mathrm{t}}\right)
$$

where $\mathrm{H}_{\mathrm{t}}=\left(\mathbf{B}_{\mathrm{t}-1}, \mathbf{T}_{\mathrm{t}}, \mathrm{T}_{\mathrm{t}-1}\right), \delta$ is a vector of parameters, $\mathbf{B}_{\mathrm{t}-1}$ is a vector of predetermined variables contained in the information set of the central bank at time $\mathrm{t}-1$, and $\Phi($.$) is the cumulative \mathrm{N}(0,1)$ distribution.

\section{Empirical analysis}

The main features of the data are briefly reported in Figures 1 to 3. Figure 1 plots the intervention intervals in days where the duration of no interventions appears in the vertical axis and dates in the horizontal axis. For convenience, we split Figure 1 into two panels. The first panel corresponds to the period 1984-1986, when the duration was short and there was a big outlier (see more on this below) while the second panel refers to the period 1987-1998 when duration was longer. Figure 2 reports the number of interventions by month whilst Figure 3 presents the histogram of the daily changes in the interest rate target, in both cases for the whole sample.

During the sample period there have been 700 target changes and the number of no-intervening periods exceeding one month $\left(X_{t}=0\right)$ are 39 . The average duration between interventions is 7.85 days and duration almost doubles for the second part of the sample. The longest duration is 181 days and corresponds to the period between November 14, 1985 and March 5, 1986 when the transition from a monetary aggregate-based control scheme to an interest-rate scheme rule was being completed.

Next, we describe the choice of predetermined variables $\left(B_{t-1}\right)$. That choice will be guided by the type of variables which are typically considered in the literature on the estimation of "Taylor rules" (see Clarida et al., 1998) The key result in that literature is that the central bank adjusts interest rates as a reaction to changes in inflation and output from some targeted values with

${ }^{2}$ The idea of including both $T_{t}$ and $T_{t-1}$ is that the central bank may consider a moving average of durations when implementing an interest rate change. The presence of further lags in the specificatio of (3) was tested without finding them statistically significan.

${ }^{3}$ See Maddala (1983) for further details on the various probit models estimated throughout this paper.

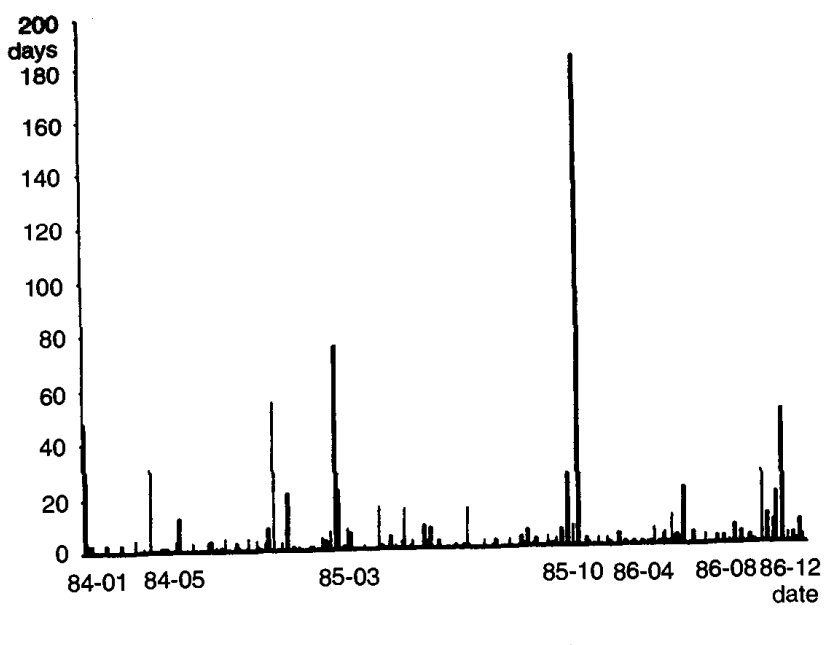

Sample period : 1984-1986

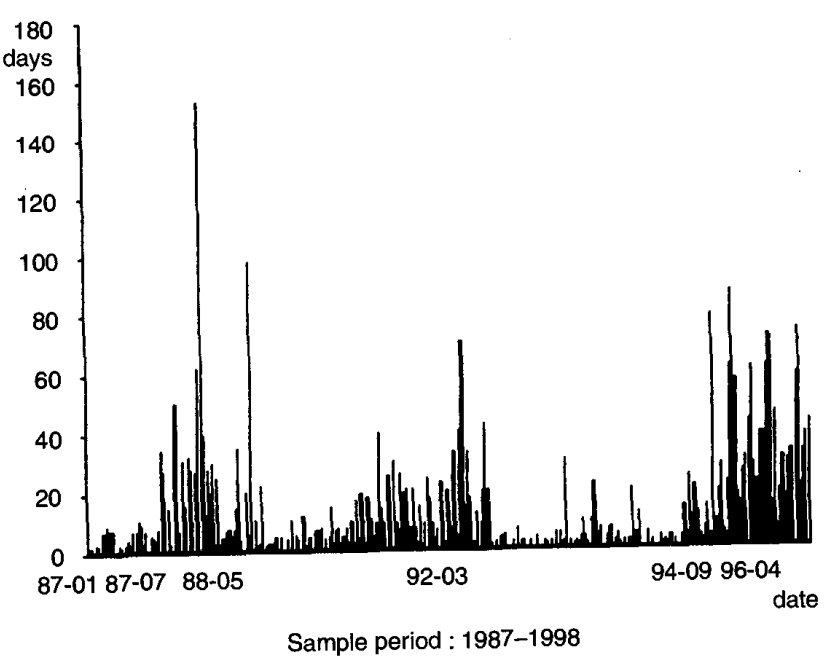

Figure 1. Duration in central bank intervention in interest rates (days)

me concern for financial markets fragility manifested by the existence of some degree of persistence in the policy rule. Moreover, since the Bank of Spain executed monetary-policy control over most of the sample in a quasifpain ex ar a member of the 


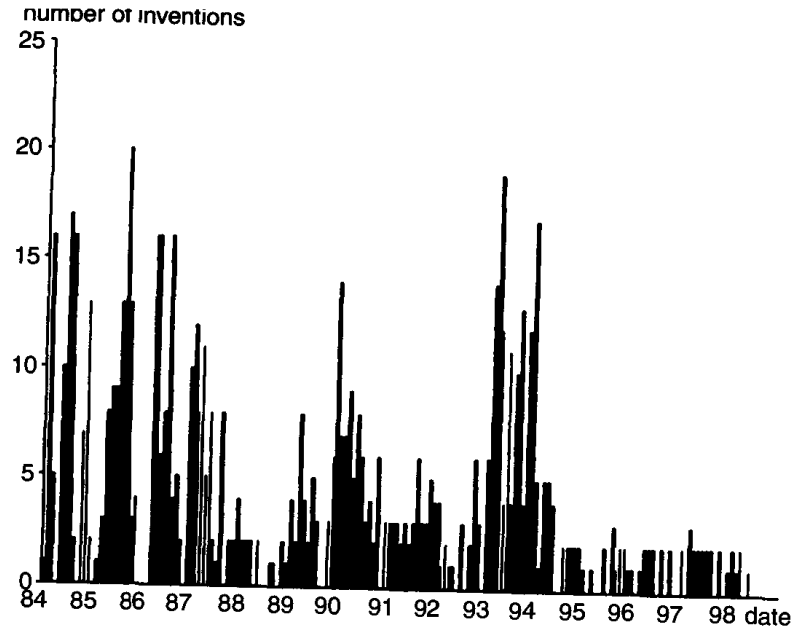

Figure 2. Number of interventions in interest rate by month

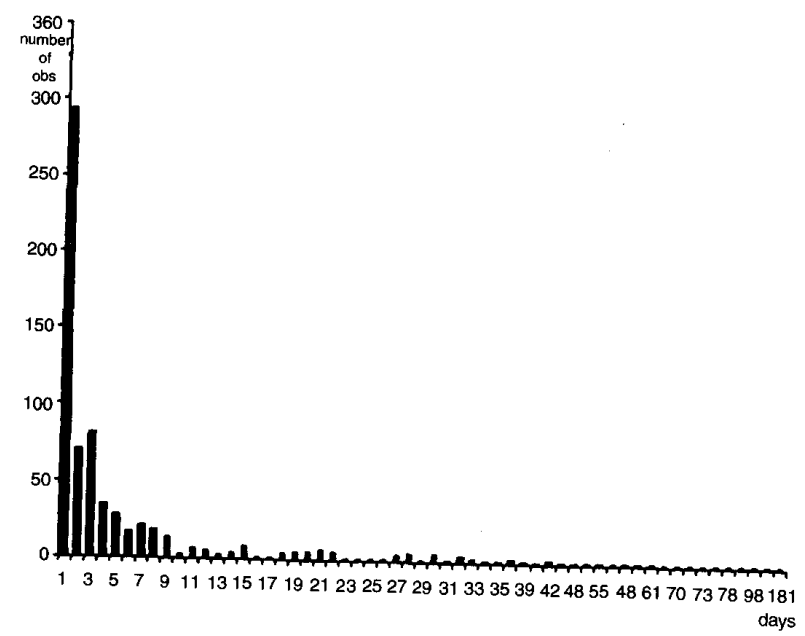

Figure 3: Duration in days histogram

EMS, exchange rates variations are also included in the policy rule. Finally, let us remark that the Bank of Spain, in common with the Bundesbank, let followed a so-called two-pillar strategy for the control of monetary during some parts of the sample. This strategy implies that a prominent role has been given to money growth, alongside a broad-based battery of other leading indicators, to forecast future inflation developments. Thus, past deviations of money growth rates from a target value are also added among the determinants of the monetary-policy stance. With all those considerations in mind, and given the limited availability of macroeconomic data at the monthly frequency, the following variables have been specifically included in monthly frequency, the following variables have been specifically included in
the information set: (lagged) changes in the CPI inflation rate $(\pi)$, (lagged) changes in the Industrial Production Index $(q)^{4}$, (lagged) changes in (log of Pta/DM exchange rate (e), lagged deviations of a monetary aggregate (ALP) growth rate from the target rate $(\widetilde{\mathrm{m}})$, and, lagged changes in the interest rate (r). All variables are seasonally adjusted.

Initially, all the predetermined variables are transformed by their absolute value. The main reason for using this transformation is that an interesting preliminary exercise is to analyse how the predetermined variables influence events in 'magnitude'. Later, in section 3.2, the possibility of having different responses according to the 'sign' of those variables will also be considered when the analysis is extended to allow for the presence of asymmetries in the reaction function of the central bank.

Hence, the initial specification of (3) is taken to be:

$$
\mathbf{F}\left(\delta^{\prime} \mathbf{H}_{\mathrm{t}}\right)=\Phi\left(\delta^{\prime} \mathbf{H}_{\mathrm{t}}\right)=\Phi\left(\delta_{0}+\delta_{\mathrm{T} 0} \mathbf{T}_{\mathbf{t}}+\delta_{\mathrm{T} 1} \mathbf{T}_{\mathrm{t}-1}+\delta_{\mathrm{m}}\left|{\widehat{\Delta \mathrm{m}_{\mathrm{t}-1}}}\right|\right.
$$$$
\left.+\delta_{\mathrm{e}}\left|\Delta \mathrm{e}_{\mathrm{t}-1}\right|+\delta_{\pi}\left|\Delta \pi_{\mathrm{t}-1}\right|+\delta_{\mathrm{q}}\left|\Delta \mathrm{q}_{\mathrm{t}-1}\right|+\delta_{\mathrm{r}}\left|\Delta \mathrm{r}_{\mathrm{t}-1}\right|\right) \text {. }
$$

Table 1 reports the results obtained from estimating two slightly different specifications of equation (4). The first specification is one where responses are assumed to be invariant over the whole sample period whereas the second model allows for different responses across relevant historical subperiods. We estimate this second specification to allow for the possibility that some of the estimated responses may have changed during the sample period as a result of significant regime shifts due to either changes in the monetary-policy contro erating. In this respect, the narrative evidence about the evolution of the monetary-control procedure in Spain and some recursive-estimation results led us to consider 1987: 01 and 1992: 03 as the two potential break-points. The first date was chosen because there is evidence that at that time the Bank of Spain implemented a change in the monetary-policy-control procedure shifting from targeting the growth rate a money aggregate (ALP) to using explicitly an 1997). The choice of the second date in turn, is motivated both by the official announcement of the 
TABLE 1

A probit model for interest-rate changes Sample period: January 1984-December 1998

\begin{tabular}{lcr}
\hline Variable & Coefficient $^{1}$ & \multicolumn{1}{c}{ Coefficient $^{2}$} \\
\hline$T_{t}$ & $0.011(1.53)$ & $0.013(2.29)$ \\
$T_{t} * d 87$ & - & $-0.003(1.52)$ \\
$T_{t-1}$ & $0.021(3.24)$ & $0.088(2.48)$ \\
$T_{t-1} * d 87$ & - & $-0.019(2.25)$ \\
$\left|\widetilde{\Delta m}{ }_{t-1}\right|$ & $0.091(2.88)$ & $0.198(1.69)$ \\
$\left|\Delta \tilde{m}_{t-1}\right| * d 87$ & - & $-0.119(2.08)$ \\
$\left|\Delta e_{t-1}\right|$ & & $0.364(1.66)$ \\
$\left|\Delta e_{t-1}\right| * d 92$ & - & $-0.346(1.70)$ \\
$\left|\Delta \pi_{t-1}\right|$ & $-024(2.31)$ & $0.282(1.94)$ \\
$\Delta \pi_{t-1} \mid * d 92$ & - & $0.527(2.66)$ \\
$\left|\Delta q_{t-1}\right|$ & $-0.482(2.46)$ & $0.013(1.67)$ \\
$\left|\Delta r_{t-1}\right|$ & $0.392(2.97)$ & $0.410(1.65)$ \\
$\left|\Delta r_{t-1}\right| * d 87$ & - & $0.354(2.45)$ \\
constant & $-1.239(12.17)$ & $-1.118(9.44)$ \\
Log - Likelihood & 337.97 & 358.30 \\
No of observations & 739.00 &
\end{tabular}

Note: (1) and (2) denotes a probit model without and with break-points, respectively. Heteroskedasticity-robust t-ratios in parentheses

Bank of Spain's adoption of an inflation target and by the changes in the width of the Pta/Ecu band of fluctuation, from $12 \%$ to $30 \%$, which followed the EMS crisis in September of 1992. For each of the two potential break-points, we constructed dummy variables, denoted as $\mathrm{d} 87$ and $\mathrm{d} 92$, respectively, which were intersected with some of the regressors in the following way. The first dummy was intersected with $\Delta \widetilde{\mathrm{m}}$ and $\mathrm{T}$ in order to capture shifts in the response of the central bank to past money-growth deviations and duration. As for the second dummy, we intersected it with $\Delta \mathrm{e}$ and $\Delta \pi$, given that the interest-rate reaction by the central bank to both variables was deemed to change in view of the events that took place in that year.

From the results shown in Table 1 , it can be observed that, in both specifications, the probability of implementing a change in the interest-rate target responds positively and significantly (at least at $10 \%$ level) to the absolute-value changes in all the explanatory variables. Moreover, they fit the data fairly well, with goodness-of-fit measures of 0.50 and 0.61 in the first and second models, respectively. An interesting result is that the probability of an adjustment depends positively on the time elapsed from the last intervention, namely, that the longer the period of inaction was, the higher the probability of a change would be. In particular, the size of the estimated coefficients on $T_{t}$ and $T_{t-1}$ in the first model seems to indicate that the probability of adjustment depends on a weighted average on current and lagged duration with weights about one-third and two-thirds, respectively. The fact the coefficient on this weighted average is positive indicates ively. The contrast to the 'self-exciting' behaviour found by Fisher and Zurlinden (1998) for exchange-rate interventions, interest-rate adjustments by the Bank of Spain have not been bunched.

To asno in the precise To ascertin the size of the prevility of implementing an interest-rate quantitative effects on the probability of implementing an interst-rate adjustment, the following simulation is carried out. First, we estimate that the (benchmark) probability of a change in the interest rate in the first model, when all the explanatory variables take a value of zero, it is 0.22 . Next, a change of 1 percentage point in each of the predetermined variables (whose change of 1 in parenthesis in the discussion below) is separately considered. name is given in parenthes. It is found Table 2 summarizes the simulated probabilities in both scenarios. It is found that the probability of a change in the interest rate increases from 0.22 to 0.32 (inflation), 0.23 (exchange rate), 0.24 (deviations in money growth) and 0.23 (industrial production), respectively. Further, to evaluate the size of the duration effect, we have computed the effect of assuming that 50 days have duration the probability of elapsed since the las from 0.22 to 0.33 . In sum the overall evidence obtained adjustment increases from 0.22 to 0.33 . In sum, he overall evidence obt from this exercise seems to point out that both inflation changes and the duration since the last adjustment are the two most relevant factors in explaining the arrival times of interest rate changes.

TABLE 2

Effects of changes in predermined variables on the probability of adjustment ( $\rho$ ) Model without break-points

\begin{tabular}{|c|c|c|c|}
\hline Change & \multicolumn{2}{|r|}{ Initial probability } & Final probability \\
\hline$\overline{T_{t}}=50$ & & 0.225 & 0.334 \\
\hline$\left|\widetilde{\Delta m_{t-1}}\right|=0.01$ & & 0.225 & 0.240 \\
\hline$\left|\Delta e_{t-1}\right|=0.01$ & & 0.225 & 0.228 \\
\hline$\left|\Delta \pi_{t-1}\right|=0.01$ & & 0.225 & 0.319 \\
\hline$\left|\Delta q_{t-1}\right|=0.01$ & & 0.225 & 0.227 \\
\hline$\left|\Delta r_{t-1}\right|=0.01$ & & 0.225 & \\
\hline \multicolumn{4}{|c|}{ Model with break-points (b-p) } \\
\hline Change & Initial $\rho$ & Final $\rho$ before $b-p$ & Final $\rho$ after $b-p$ \\
\hline$\overline{T_{t}}=50$ & 0.246 & 0.385 & 0.350 \\
\hline$\left|\widetilde{\Delta m_{t-1}}\right|=0.01$ & 0.246 & 0.284 & 0.261 \\
\hline$\left|\Delta e_{t-1}\right|=0.01$ & 0.246 & 0.319 & 0.249 \\
\hline$\left|\Delta \pi_{t-1}\right|=0.01$ & 0.246 & 0.302 & 0.423 \\
\hline$\left|\Delta q_{t-1}\right|=0.01$ & 0.246 & 0.249 & 0.249 \\
\hline$\left|\Delta r_{t-1}\right|=0.01$ & 0.246 & 0.330 & 0.412 \\
\hline
\end{tabular}


With regard to the second model, we compute benchmark probability of 0.25 . An interesting finding is that the response to inflation changes turns out to be much larger after 1992 than before $(0.30$ and 0.42 , respectively), a the Bank of Spain in the run-up to EMU. This result seems to support the more 'aggressive' approach to reduce inflation which is characteristically found in the estimation of 'Taylor rules' (a coefficient on inflation greater than unity) for Spain in samples starting in the mid-1990s (see Dolado et al, 2001b). By contrast, regarding the response to the Pta/DM exchange rate, we find the opposite, namely, that the response was larger before 1992 than afterwards ( 0.32 and 0.25 , respectively), in accord with the increase in the width of the fluctuation bands of the EMS that took place in that year. As regards the effect of the duration variable, we find it to be marginally larger before 1987 than after $(0.39$ and 0.35 , respectively). Finally, the relative strength of the responses to past changes in interest rate and in money-growth deviations is found to shift in opposite directions after the , while the probability of an in lagged changes in interest rates was larger after 1987 than before 0.33 and 0.41 , respectively), the opposite occurs with the response to money growth deviations ( 0.28 and 0.26 , respectively). This result is in accord with the shift in the strategy of monetary-policy control which the Bank of Spain underwent in that year.

\section{Analysis of asymmetries}

In this section, the previous analysis is extended to examine the possible existence of asymmetries in the timing of interventions by the Bank of Spain in response to its determinants. For that purpose, the probit model is respecified so that the coefficients on the predetermined variables are now allowed to depend on the 'sign' of the changes. ${ }^{5}$ For this purpose, positive and negative changes are now associated to two coefficients on each variable, $\delta^{+}$ and $\delta^{-}$, respectively. The null hypothesis of symmetry, $\mathrm{H}_{0}: \delta^{+}=\delta^{-}$, is then tested using a standard Likelihood Ratio (LR) test.

The results, which are not reported in detail for the sake of brevity, can be summarised as follows. ${ }^{6}$ First, the probability of an interest-rate adjustment is found to be larger when inflation accelerated than when it decelerated (p-value $=0.01$ ). This seems to reflect the fact that during the sample period

${ }^{5} \mathrm{~A}$ referee pointed out that asymmetries may also arise from the interaction of independent variables. We also pursued that route by interacting the inflation and output growth rates with the exchange-rote regime in phee, but did not find any significant efect stemming from that variabe

${ }^{6}$ Detailed results are available upon request disinthaton was accompanied by a parallel reduction in the number of interestrate adjustments. Secondly, we observe that the Bank of Spain reacted more forcefully to depreciations of the Pta/DM exchange rate than to appreciations, in order to prevent inflation pressure. Thirdly, in response to changes in output, the probability of an interest rate change is larger when the economy output, the probability of an interest rate change is larger when the economy
is in a downturn than in an upturn (p-value $=0.04)^{7}$ Fourthly, no asymmetric behaviour is found in the response to money-growth deviations (p-value $=0.08$ ). This result could again be explained by the loss of significance of this variable in the monetary-control strategy implemented after 1987. Finally, it is found that adjustments are less likely to take place in situations when the interest rate increased in the last period than when it decreased $(p$-value $=0.04)$. This seems to indicate that there has been more persistence in lowering interest rates than in raising them.

\section{Analysis of marks: Size of interest-rate changes}

This section is devoted to modelling the density of the marks, denoted as $\mathrm{f}_{2}$ in equation (2), conditional on the events and on the set of predetermined variables which determine monetary-policy instrumentation. Following Jordá (1997) and Hamilton and Jordá (2000), we use an ordered probit model since such a model can be viewed as a natural generalisation of a dynamic linear regression model to the case where the dependent variable is discrete Accordingly, we only need to consider that the interest rate takes a finite number of values which possess a natural ordering.

We assume that the marks of a marked point process are only observed at each event time. That is, at times $1, \ldots, i_{t}, \ldots \mathrm{N}$, we observe the magnitude of the target changes given by $\mathrm{Y}_{1}, \mathrm{Y}_{2}, \ldots, \mathrm{Y}_{\mathrm{N}}$. At any other time, $\mathrm{Y}$ is no observed. Then, let $\mathrm{Y}_{\mathrm{i}}^{*}$ be an unobservable continuous random variable such that:

$$
\mathrm{Y}_{\mathrm{i}}^{*}=\mathrm{w}_{\mathrm{i}}^{\prime} \gamma+\varepsilon_{\mathrm{i}} \quad \mathrm{E}\left[\varepsilon_{\mathrm{i}} / \mathrm{w}_{\mathrm{i}}\right]=0
$$

where $w_{i}=\left(T_{i}, Y_{i-1}, B_{i}\right)$ and $\varepsilon_{i}$ is an error-term distributed as $N(0,1)$. As in the previous section, the vector of variables $B$ is assumed to be observed with one period lag. The key assumption underlying the ordered logit model is that the observed interest-rate changes, $Y_{i}$, are related to the continuous latent variable, $\mathrm{Y}_{\mathrm{i}}^{*}$, in the following way:

${ }^{7}$ When interpreting the asymmetric effects from output changes one should bear in mind that the growth rate of industrial production (in deviation from its average value, captured by the constan

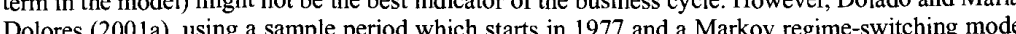
to estimate GDP business cycles more accurately, find evidence in favour of such an asymmetry. 


$$
Y_{i}=\left[\begin{array}{cl}
s_{1} & \text { if } Y_{i}^{*} \in A_{1} \\
s_{2} & \text { if } Y_{i}^{*} \in A_{2} \\
\cdots & \text { if } Y_{i}^{*} \in A_{m-1} \\
s_{m-1} & \text { if } Y_{i}^{*} \in A_{m} \\
s_{m} & ,
\end{array}\right.
$$

where the sets $A_{j}$ partition the domain of $Y_{i}^{*}$ such that $A_{i} \frown A_{j}=\emptyset$ for $i \neq j$

The $s_{j}$ are the observed discrete values of the variable $Y_{i}$ and the partition of the domain of $Y_{i}^{*}$ into subsets is such that:

$$
\begin{aligned}
A_{1} \equiv & \left(-\infty, c_{1}\right) \\
A_{2} \equiv & \left(c_{1}, c_{2}\right) \\
& \cdots \\
A_{m} \equiv & \left(c_{m-1}, \infty\right)
\end{aligned}
$$

Therefore, the distribution of the observed interest rate changes conditional on $\mathrm{w}_{\mathrm{i}}$ becomes:

$$
\begin{aligned}
\mathrm{P}\left(\mathrm{Y}_{\mathrm{i}}=\mathrm{s}_{\mathrm{j}} / \mathrm{w}_{\mathrm{i}}\right) & =\mathrm{P}\left(\mathrm{w}_{\mathrm{i}}^{\prime} \gamma+\varepsilon_{\mathrm{i}} \in \mathrm{A}_{\mathrm{j}}\right) \\
& =\left[\begin{array}{ll}
\mathrm{P}\left(\mathrm{w}_{\mathrm{i}}^{\prime} \gamma+\varepsilon_{\mathrm{i}} \leq \mathrm{c}_{\mathrm{l}}\right) & \text { if } \mathrm{j}=1 \\
\mathrm{P}\left(\mathrm{c}_{\mathrm{j}-1}<\mathrm{w}_{\mathrm{i}}^{\prime} \gamma+\varepsilon_{\mathrm{i}} \leq \mathrm{c}_{\mathrm{j}}\right) & \text { if } 1<\mathrm{j}<\mathrm{m}, \\
\mathrm{P}\left(\mathrm{c}_{\mathrm{j}}<\mathrm{w}_{\mathrm{i}}^{\prime} \gamma+\varepsilon_{\mathrm{i}}\right) & \text { if } \mathrm{j}=\mathrm{m}
\end{array}\right.
\end{aligned}
$$

which, under the assumption of normality, yields:

$$
\left[\begin{array}{ll}
\Phi\left(\varepsilon_{\mathrm{i}} \leq \mathrm{c}_{1}-\mathrm{w}_{\mathrm{i}}^{\prime} \gamma\right) & \text { if } \mathrm{j}=1 \\
\Phi\left(\varepsilon_{\mathrm{i}} \leq \mathrm{c}_{\mathrm{j}}-\mathrm{w}_{\mathrm{i}}^{\prime} \gamma\right)-\Phi\left(\varepsilon_{\mathrm{i}} \leq \mathrm{c}_{\mathrm{j}-1}-\mathrm{w}_{\mathrm{i}}^{\prime} \gamma\right) & \text { if } 1<\mathrm{j}<\mathrm{m}, \\
1-\Phi\left(\varepsilon_{i} \leq \mathrm{c}_{-1}-\mathrm{w}^{\prime} \gamma\right) & \text { if } \mathrm{j}=\mathrm{m}
\end{array}\right.
$$

where $\Phi(\eta)$ is defined as:

$$
\Phi(\eta)=\int_{-\infty}^{\eta} \exp \left(-\varepsilon^{2} / 2\right) \mathrm{d} \varepsilon \text { for } \eta=\mathrm{c}_{\mathrm{j}}-\mathrm{w}_{\mathrm{i}}^{\prime} \gamma .
$$

The intuition behind the ordered probit model is simple: the probability of any particular observed target change is determined by where the conditional mean lies relative to the partition boundaries, $c_{j}$. Given this partition, a higher conditional mean implies a higher probability of observing a more extreme positive state. Hence, for example, if an increase in inflation leads to a upward interest-rate adjustment, we should expect the coefficient associated with the inflation variable to be positive.
To specify the likelihood, we use an indicator variable, $\mathrm{I}_{\mathrm{i}}^{\mathrm{j}}$, which takes the value of 1 if $Y_{i}=s_{j}$, and 0 otherwise. Then, the log-likelihood of the magnitude of the interest-rate adjustments, conditional on the explanatory variables becomes ${ }^{8}$ :

$$
\mathfrak{E}(\mathrm{Y} / \mathrm{w})=\sum_{\mathrm{i}=1}^{\mathrm{N}}\left\{\begin{array}{c}
\mathrm{I}_{\mathrm{i}}^{1} \log \Phi\left(\mathrm{c}_{1}-\mathrm{w}_{\mathrm{i}}^{\prime} \gamma / \sigma\right)+ \\
\sum_{\mathrm{j}=1}^{\mathrm{m}-1} \mathrm{I}_{\mathrm{i}}^{\mathrm{j}} \log \left[\Phi\left(\mathrm{c}_{\mathrm{k}}-\mathrm{w}_{\mathrm{i}}^{\prime} \gamma / \sigma\right)-\Phi\left(\mathrm{c}_{\mathrm{k}-1}-\mathrm{w}_{\mathrm{i}}^{\prime} \gamma / \sigma\right)\right] \\
+\mathrm{I}_{\mathrm{i}}^{\mathrm{m}} \log \left[1-\Phi\left(\mathrm{c}_{\mathrm{m}-1}-\mathrm{w}_{\mathrm{i}}^{\prime} \gamma / \sigma\right)\right]
\end{array}\right\}
$$

\section{Empirical results}

In order to estimate the ordered probit model, a preliminary step is to define the number of categories of the observed interest-rate changes. Since the average change in the data is around 25 basis points, we have used the following classification:

$$
\left\{\begin{array}{l}
\text { if } \quad y_{i} \leq-0.625 \text { then } \tilde{y}_{i}=-0.75 \\
\text { if } \quad-0.625<y_{i} \leq-0.375 \text { then } \tilde{y}_{i}=-0.5 \\
\text { if } \quad-0.375<y_{i} \leq-0.125 \text { then } \tilde{y}_{i}=-0.25 \\
\text { if } \quad-0.125<y_{i} \leq 0.125 \text { then } \tilde{y}_{i}=0 \\
\text { if } \quad 0.125<y_{i} \leq 0.375 \text { then } \tilde{y}_{i}=0.25 \\
\text { if } \quad 0.375<y_{i} \leq 0.625 \text { then } \tilde{y}_{i}=0.5 \\
\text { if } \quad y_{i}>0.625 \text { then } \tilde{y}_{i}=0.75
\end{array}\right.
$$

where $\tilde{y}_{i}$ refers to the aggregated series while $y_{i}$ is the original series. As a result of this procedure, six intercepts need to be estimated. Thus, we have:

$$
\mathrm{y}_{\mathrm{i}}^{*}=\mathrm{w}_{\mathrm{i}} \cdot \gamma+\varepsilon_{\mathrm{i}} \quad \text { where } \varepsilon_{\mathrm{i}} \sim \operatorname{nid}(0, \sigma),
$$

where $\tilde{y}_{i}=\{-0.75,-0.5,-0.25,0,0.25,0.5,0.75\}$. Given the composition of $B_{i}$ discussed in the previous section, we specify (5) as follows':

$$
\begin{aligned}
\mathrm{y}_{\mathrm{i}}^{*}= & \gamma_{\mathrm{y}} \tilde{\mathrm{y}}_{\mathrm{i}_{t-1}}+\gamma_{\mathrm{T}} \mathrm{T}_{\mathrm{i}_{\mathrm{t}}}+\gamma_{\mathrm{m}} \widetilde{\Delta \mathrm{m}_{\mathrm{i}_{t-1}}}+\gamma_{\mathrm{e}} \Delta \mathrm{e}_{\mathrm{i}_{t-1}} \\
& +\gamma_{\pi} \pi_{\mathrm{i}_{\mathrm{t}-1}}+\gamma_{\mathrm{q}} \mathrm{q}_{\mathrm{i}_{\mathrm{t}-1}}+\varepsilon_{\mathrm{i}} .
\end{aligned}
$$

The estimation results are presented in Table 3. As before, we allowed for break-points in 1987 and 1992. Overall we find the signs of the estimated coefficients to be broadly in agreement with a priori beliefs. Thus, it is found that changes in inflation and output, money-growth deviations and depreci${ }^{8}$ Since $\sigma$ is not separately identifiable, the estimation proceeds under the standard normalization ${ }^{\circ}$ Lagged duration was also considered but never showed up statistically significant. 
TABLE 3

An ordered probit model for interest-rate changes Sample period: January 1984-December
1998

\begin{tabular}{lcc}
\hline Coefficient & Estimated Value & $t$-statistic \\
\hline$\gamma_{y}$ & 0.245 & 2.99 \\
$\gamma_{T}$ & 0.023 & 1.69 \\
$\gamma_{T} * d 87$ & -0.011 & 2.23 \\
$\gamma_{m}$ & 0.272 & 2.38 \\
$\gamma_{m} * d 87$ & -0.200 & 2.05 \\
$\gamma_{e}$ & 0.491 & 1.71 \\
$\gamma_{e} * d 92$ & -0.467 & 1.63 \\
$\gamma_{\pi}$ & 0.051 & 2.50 \\
$\gamma_{\pi} * d 92$ & 0.041 & 1.92 \\
$\gamma_{q}$ & 0.023 & 1.91 \\
$c_{1}$ & -1.275 & 6.70 \\
$c_{2}$ & -0.859 & 4.67 \\
$c_{3}$ & 0.156 & 1.86 \\
$c_{4}$ & 1.047 & 5.73 \\
$c_{5}$ & 2.059 & 10.39 \\
$c_{6}$ & 2.299 & 11.68 \\
Log-Likelihood & 1135.22 & - \\
No. of observations & 700 & \\
\hline
\end{tabular}

ations of the Pta/DM exchange rate tend to increase the magnitude of interest rates changes. The estimated effects of both changes in inflation and exchange rate depreciation are larger after 1992, whereas, the effects of money-growth deviations and duration are smaller after 1987. Note that the positive estimated coefficient on the duration variable, $\gamma_{\mathrm{T}}$, implies that the longer the durations since the last change was the larger the change in the interest rate tended to $\mathrm{be}^{10}$. Finally, we find that the coefficient on the lagged change in the interest mate is positive and strongly significant ${ }^{11}$

In this framework, as Jordá (1997) has pointed out, it is interesting to test for another type of 'duration effect', namely, whether long spells without intervention might cause larger changes in interest rates than frequent adjustments. To implement this test, we construct the following indicator variable distinguishing between shorter and larger duration than 15 days: ${ }^{12}$

$$
\left\{\begin{array} { l l } 
{ d _ { i } ^ { l } = 1 } & { \text { if } T _ { i } > 1 5 } \\
{ d _ { i } ^ { l } = 0 } & { \text { otherwise } }
\end{array} \quad \text { and } \quad \left\{\begin{array}{ll}
d_{i}^{s}=1 & \text { if } T_{i}<=15 \\
d_{i}^{s}=0 & \text { otherwise }
\end{array}\right.\right.
$$

${ }^{10}$ The goodness of fit in this model is 0.441 but when we aggregate data in three categories according to sign (negative, zero and positive), it increases to 0.6466 .

${ }^{11}$ This is in accordance with the obtained result by Rudebusch(1995) for the Fed-Funds rate.
${ }^{2}$ The choice of 15 days corresponds to about two standard deviations of the data
Next we construct the following intersected variables: $I_{i}^{1}=d_{i} * I_{i}$ and $\mathbf{T}^{\mathbf{s}}=\mathrm{d}^{\mathbf{s}} * \mathrm{~T}_{\mathrm{i}}$. $\gamma^{1}$ and $\gamma_{\mathrm{s}}^{\mathrm{s}}$ be coefficients associated with $\mathrm{T}_{\mathrm{T}}^{\mathrm{a}}$ and $\mathrm{T}_{\mathrm{s}}^{\mathrm{s}}$ respectively. Then, rejection of the null hypothesis $H_{0}: \gamma_{T}^{l}=\gamma_{T}^{s}$ will provide evidence in favour of such a 'duration effect'. Having implemented a LR test in this model, we do find favourable evidence for that effect, having rejected the null hypothesis with a p-value of 0.007 .

Finally, we test for 'sign' asymmetries in the previous 'duration effect', namely, the possibility that this effect may depend on whether the interest rate is being increased or decreased. Testing for this asymmetry might be particularly interesting since it is sometimes argued that delays by the central particularly interesting since it is sometimes argued that delays by the central bank in cutting interest rates, when they are considered to be appropriate, may
be more costly, in terms of achieving economic stability, than delays in raising interest rates. In other words, it might be worse in welfare terms to delay the provision of a stimulus to the economy when it enters a slowdown than to postpon a rise in intert rates when there are signs of overheating in an anther indicator variable that depends on whether the output growth rate is positive or negative, so as to capture upturns and downturns:

$$
\left\{\begin{array} { l l } 
{ d _ { i } ^ { + } = 1 } & { \text { if } \Delta \mathrm { q } _ { \mathrm { i } } \geq 0 } \\
{ d _ { i } ^ { + } = 0 } & { \text { otherwise } }
\end{array} \quad \text { and } \quad \left\{\begin{array}{ll}
d_{i}^{-}=1 & \text { if } \Delta \mathrm{q}_{\mathrm{i}}<0 \\
d_{i}^{-}=0 & \text { otherwise }
\end{array}\right.\right.
$$

As before, the following two intersected variables are constructed $\mathbf{T}_{\mathrm{i}}^{+}=\mathbf{d}_{\mathrm{i}}^{+} * \mathbf{T}_{\mathrm{i}}$ and $\mathbf{T}_{\mathrm{i}}^{-}=\mathrm{d}_{\mathrm{i}}^{-} * \mathbf{T}_{\mathrm{i}}$ where $\gamma_{\mathrm{T}}^{+}$and $\gamma_{\mathrm{T}}^{-}$are the coefficients associated with $T_{i}^{+}$and $T_{i}^{-}$. Then, rejection of the null hypothesis $\mathrm{H}_{0}: \gamma_{\mathrm{T}}^{+}=\gamma_{\mathrm{T}}^{-}$is interpreted as evidence against symmetric behaviour. Using a $L R$ ratio test, we reject the null hypothesis with a p-value of 0.02 . Hence, an asymmetric behaviour is found again. Indeed, though not reported, the astime strongly significant, a result that seems to suggest that, in contrast to the argument discussed above, the Bank of Spain has been more prone to rais interest rates in order to avoid episodes of overheating in the Spanish economy than to fight recessions through interest-rate cuts.

\section{Events and Marks: A sequential probit model}

In the previous sections, the marginal and the conditional distributions, $f_{1}$ and $f_{2}$ in (2), have been estimated in a separate way. To test whether the obtained results remain robust to a joint-estimation procedure, we use a sequential probit model to jointly estimate the parameters in the densities for events and marks. We assume that the central bank makes a joint decision on whether to change the target rate $(X=1)$ or leave it unchanged $(X=0)$ and, in 


$$
\mathrm{p}\left(\mathrm{X}_{\mathrm{t}}=0 / \mathrm{B}_{\mathrm{t}-1}, \mathrm{~T}_{\mathrm{t}}, \mathrm{T}_{\mathrm{t}-1}\right)=\Phi\left(-\delta^{\prime} \mathrm{H}_{\mathrm{t}}\right),
$$

in the case of no adjustment and

$$
\mathrm{p}\left(\mathrm{Y}_{\mathrm{i}}=\mathrm{s}_{\mathrm{j}} / \mathrm{w}_{\mathrm{i}}\right)=\mathrm{p}\left(\mathrm{X}_{\mathrm{t}}=1 / \mathrm{B}_{\mathrm{t}-1}, \mathbf{T}_{\mathrm{t}}, \mathbf{T}_{\mathrm{t}-1}\right) * \mathrm{p}\left(\mathrm{w}_{\mathrm{i}}^{\prime} \gamma+\varepsilon_{\mathrm{i}} \in \mathrm{A}_{\mathrm{j}}\right),
$$

in the case of an adjustment. This leads to the following likelihood function, where $\mathrm{j}$ is defined as above.

$$
\left[\begin{array}{ll}
\left(1-\Phi\left(-\delta^{\prime} \mathrm{H}_{\mathrm{t}}\right)\right) \Phi\left(\varepsilon_{\mathrm{i}} \leq \mathrm{c}_{1}-\mathrm{w}_{\mathrm{i}}^{\prime} \gamma\right) & \text { if } \mathrm{j}=1 \\
\left(1-\Phi\left(-\delta^{\prime} \mathrm{H}_{\mathrm{t}}\right)\right)\left(\Phi\left(\varepsilon_{\mathrm{i}} \leq \mathrm{c}_{\mathrm{j}}-\mathrm{w}_{\mathrm{i}}^{\prime} \gamma\right)-\Phi\left(\varepsilon_{\mathrm{i}} \leq \mathrm{c}_{\mathrm{j}-1}-\mathrm{w}_{\mathrm{i}}^{\prime} \gamma\right)\right) & \text { if } \mathrm{l}<\mathrm{j}<\mathrm{m} \\
\left(1-\Phi\left(-\delta^{\prime} \mathrm{H}_{\mathrm{t}}\right)\right)\left(1-\Phi\left(\varepsilon_{\mathrm{i}} \leq \mathrm{c}_{\mathrm{j}-1}-\mathrm{w}_{\mathrm{i}}^{\prime} \gamma\right)\right) & \text { if } \mathrm{j}=\mathrm{m}
\end{array}\right.
$$

Hence, the parameters of the model can be estimated through the maximisation of the joint likelihood function in equations (15) and (17). Note, however, that such a joint-maximisation procedure is not exactly equivalent to maximising the sum of the log-likelihoods corresponding to the probit and ordered probit models, respectively. This is due to the fact that the joint-maximisation procedure involves all the observations, namely 739 , which are also used to estimate the marks whereas the separate estimation of the events only involves the 700 observations involving adjustments.

\section{Empirical results}

Table 4 shows the estimated parameters obtained from the sequential probit model. Our approach is to compare them to those obtained from the separate estimation procedures, as presented in Tables 1 and 3. Though a formal statistical test is not yet available in order to check how close the two sets of estimates and their precisions are, it can be noticed that the results in Table 4 are fairly similar to those obtained separately in the probit (for events) and ordered probit (for marks ) models ${ }^{13}$, respectively. Thus, the main qualitative and quantitative conclusions reached before remain overall unchanged. For example, we find again that an interest-rate adjustment is more likely to take place when inflation increases than when it decreases

${ }^{13}$ Moreover, the correlation between the residuals in the estimated models for events and marks is small (0.1345), which also supports the consistency of estimates obtained in the separate estimation procedure.
TABLE 4

A sequential probit model for interest-rate changes Sample period: January 1984-December 1998

\begin{tabular}{lclr}
\hline Coefficient & Probit & Coefficient & Ordered Probit \\
\hline$T_{t}$ & $0.009(1.71)$ & $\gamma_{y}$ & $0.262(2.37)$ \\
$T_{t} * d 87$ & $-0.0059(1.76)$ & $\gamma_{T}$ & $0.013(2.73)$ \\
$T_{t-1}$ & $0.005(3.06)$ & $\gamma_{T} * d 87$ & $-0.001(1.94)$ \\
$T_{t-1} * d 87$ & $0.0071(2.23)$ & $\gamma_{m}$ & $0.502(2.05)$ \\
$\mid \Delta \tilde{m}$ & $0.2176(2.81)$ & $\gamma_{m} * d 87$ & $-0.419(1.66)$ \\
$\left|\Delta \widetilde{m}_{t-1}\right| * d 87$ & $-0.0906(1.79)$ & $\gamma_{e}$ & $0.093(2.08)$ \\
$\left|\Delta e_{t-1}\right| * d 92$ & $-0.092(2.64)$ \\
$\left|\Delta e_{t-1}\right| * d 92$ & $0.4664(2.49)$ & $\gamma_{e} * d 92$ & $0.067(2.10)$ \\
$\left|\Delta \pi_{t-1}\right|$ & $-0.4438(1.78)$ & $\gamma_{\pi}$ & $0.066(3.94)$ \\
$\left|\Delta \pi_{t-1}\right| * d 92$ & $0.8192(2.63)$ & $\gamma_{\pi} * d 92$ & $0.003(1.71)$ \\
$\left|\Delta q_{t-1}\right|$ & $0.0433(1.87)$ & $\gamma_{q}$ & $-1.08(17.99)$ \\
$\left|\Delta r_{t-1}\right|$ & $0.016(1.90)$ & $c_{1}$ & $-0.65(16.56)$ \\
$\left|\Delta r_{t-1}\right| * d 87$ & $0.4189(2.95)$ & $c_{2}$ & $.18(7.51)$ \\
constant & $0.3237(2.33)$ & $c_{3}$ & $1.60(11.48)$ \\
Log - Likelihood & $-1.101(13.82)$ & $c_{4}$ & $2.69(17.44)$ \\
No. of observations & 1711.38 & $c_{5}$ & $3.74(13.10)$ \\
\hline
\end{tabular}

Note: Heteroskedasticity-robust t-ratios in parentheses.

(p-value $=0.0005$ ), when the $\mathrm{Pta} / \mathrm{DM}$ exchange rate depreciates than when it appreciates $(p$-value $=0.01)$, when there are positive money-growth deviations ( $p$-value $=0.02$ ) and, finally, when the lagged interest rate is increasing ( $\mathrm{p}$-value $=0.01$ ). The only difference which is worth mentioning is that there seems to be a slightly weaker evidence in favour of asymmetric behaviour of the arrival times in response to output changes in the joint than in the separate estimation procedure, with p-values of 0.06 and 0.04 in the sectively.

As for the presence in this model of the two 'duration effects' considered As for the presence in this model of the two 'duration effects' considered
bove, we basically find the same results as in the separate estimation procedure, namely, that both effects are present, with p-values of 0.006 and 0.04 , respectively.

Hence, the overall impression that one gets from this raw 'eyeball' comparison is that the lack of weak exogeneity does not seem to be a serious problem in the empirical application at hand.

\section{Conclusions}

In this paper we use an econometric methodology based on the estimation of a marked point process to analyse the determinants of both the arrival times and the size of adjustments in a short-term interest rate used by the Bank of Spain 
tor monetary-control purposes between 1984 and 1998. In particular, we provide estimates of the effects of various macroeconomic determinants and the duration since the last intervention on the timing of interest-rate adjustments (events) and the magnitude of those adjustments (marks), conditionally on intervening. Different types of probit models have been used to estimate the relevant parameters in the densities of marks and events, both through separate and joint estimation procedures. It has been argued that a comparison of the estimates obtained through both procedures helps one to ascertain how serious the problem of lack of weak exogeneity might be when a separate estimation method is used to estimate each process. We do not find evidence against weak exogeneity in our empirical application.

Additionally, our modelling strategy proves useful to test for the presence of asymmetries in the response of the Bank of Spain, in terms of the timing and the magnitude of interest-rate adjustments, to changes in the evolution of several macroeconomic variables contained in its information set.

The results regarding the events can be summarized as follows. It is found that the probability of an interest-rate adjustment increases when: (i) there is a recession, (ii) there is an upsurge in inflation, (iii) the exchange rate depreciates, and (iv) there is a positive money-growth deviation with respect to its annual target rate. In particular, the response to 'excessive' moneygrowth rates seems to be weaker after 1987 than before, whereas the response to inflation is much stronger after 1992. Both results are in accord with the progressive adoption of an inflation-targeting strategy by the Spanish central bank in the run-up to EMU.

As for the marks, we find evidence in favour of the so-called 'duration effect' implying that long inactivity periods induce larger changes in interest rates than frequent adjustments. Thus, there is no evidence of a 'self-exciting' behaviour by the central bank in terms of implementing bunched adjustments in the policy instrument. Finally, our findings point out that the Bank of Spain seems to have been more prone to avoid overheating of the Spanish economy, by implementing large increases in interest rates during upturns, than to relax monetary-policy stance during downturns by means of sizeable interest rate cuts.

Final Manuscript received January 2002

\section{References}

Ayuso, J. and Escrivá, J. L. (1996). 'La Evolución de la Estrategia de Control Monetario en España', Servicio de Estudios del Banco de España. Documento de Trabajo 9629 Ball, L. (1999). 'Policy Rules for Open Economies', in Taylor J.B. (ed.) Monetary Policy Rules, Univ. of Chicago Press.
Clarida, R., Gali, J. and Gertler, M. (1998). 'Monetary Policy Rules in Practice: Some Clarida, R., Gali, J. and Gertler, M. (1998). 'Monetary Policy Rules in
International Evidence', European Economic Review, Vol. 42. pp. 1033-67.

Clarida, R, Gali, J and Gertler, M. (1999). 'The Science of Monetary Policy: A New Keynesian Perspective', Journal of Economic Literature, Vol. 37, pp. 1661-1707.

Davutyan, N and Parke, W. (1995). 'The Operations of the Bank of England, 1890-1908: A Dynamic Probit Approach', Journal of Money, Credit and Banking, Vol. 27, pp. 1099 1112 .

Dolado, J. and Maria-Dolores, R. (2001a). 'An Empirical Study of the Cyclical Effects of Monetary Policy in Spain (1977-1997)', Investigaciones Económicas, Vol. 25, pp. 3-30. Dolado, J., Maria-Dolores, R. and Naveira, M. (200lb). 'Are Central Banks Reaction Functions Asymmetric?: Evidence for Some Central Banks', mimeo.

Eichengreen, B., Watson, M. and Grossman, R. (1985). 'Bank Rate Policy under the Interwar Gold Standard: A Dynamic Probit Model', Economic Journal, Vol. 95, pp. 725-745. Engle, R. F., Hendry, D. F. and Richard, J. F. (1983). 'Exogeneity', Econometrica, Vol. 51, pp. 277-304.

Engle, R. F. and Russell, J. (1997). 'Forecasting the Frequency of Changes in Quoted Foreign Exchanges Prices with the ACD Model', Journal of Empirical Finance, Vol. 12, pp. 187 212.

Engle, R. F. and Russell, J. (1998). 'Autoregressive Conditional Duration: A New Model for Irregularly Spaced Transaction Data', Econometrica, Vol. 66, pp. 1127-1162.

Engle, R. (2000). 'The Econometrics of Ultra-High-Frequency Data', Econometrica, Vol. 68 , pp. 1-22.

Escrivá, J. L. and Santos, R. (1991). 'Un Estudio del Cambio de Régimen en la Variable Instrumental del Control Monetario en España', Banco de España. Servicio de Estudios. Documento de Trabajo 9111.

Fischer, A. and Zurlinden, M. (1998). 'Are Interventions Self-Exciting?'. CEPR Working Paper Series No. 1964.

Gali, J. (1999). 'La Política Monetaria Europea y sus Posibles Repercusiones sobre la Economía Española' in R. Caminal (ed.). El Euro y sus Repercusiones sobre la Economía Española, Fundación BBV.

amilton, J. and Jordá, O. (2000). 'A Model For The Federal Funds Rate Target'. NBER Working Paper Series No. 7847, 2000 .

Jorda, O. (1997). 'The Stance of Monetary Policy: The Federal Funds Rate Target: Searching in a New Direction', UCSD, mimeo.

. 'S cicication in Econometrics', Econometrica, Vol. 46, pp. 1251-1272

perala, G. S. (1983). Limited Dependent and Qualitative Variables in Econometric, Econometric Society Monographs, Cambridge University Press.

Tonetaria en Espa(A) . 391-415.

Ravn, M. and Sola, M. (1996). 'Asymmetric Effects of Monetary Policy in the US: Positive vs Negative or Big vs Small?', Mimeo. University of Aarhus, Denmark.

Rudebusch, G. (1996). 'Do Measures of Monetary Policy in VAR Make Sense?', presented as part of the conference on Monetary Policy; Measurement and Manse?', presented as 1996, Center for Economic Policy Research-Stanford University and the Federal Reserve Bank of San Francisco.

Schaling, E. (1999) 'The Non-Linear Phillips Curve and Inflation Forecast Targeting', Bank of England, Working Paper. 
Servicio de Estudios del Banco de España (1997). La Política Monetaria y la Inflación en el

Banco de España. Alianza Editorial.

Tanon, L. (1997). 'Thanion Forecast Taye 41, pp. 111-1146.

Targets', European Economic Review, Vol. 41, pp. 111-1146.

Taylor, J. (1993). 'Discretion versus Policy Rules in Practice', Carnegie-Rochester Confer-

ence on Public policy, 39. 